\title{
ИСПОЛЬЗОВАНИЕ ПРЕИМУЩЕСТВ ДОЛЖНОСТНОГО ИЛИ СЛУЖЕБНОГО ПОЛОЖЕНИЯ В ХОДЕ ИЗБИРАТЕЛЬНОЙ КАМПАНИИ КАК ФОРМА ЗЛОУПОТРЕБЛЕНИЯ ПРАВАМИ
}

\begin{abstract}
Аннотация. Предметом исследования являются общественные отношения, связанные с реализацией юридической ответственности за использование преимуществ должностного или служебного положения в период избирательной кампании. Автор рассматривает использование преимуществ должностного или служебного положения в качестве одной из форм злоупотребления правом. Особое внимание авторов Конституции Российской Федерации к гарантиям равенства прав и свобод человека и гражданина независимо от должностного положения определило появление в Федеральном законе "Об основных гарантиях избирательных прав и права на участие в референдуме граждан Российской Федерации» отдельной статьи, посвященной ограничениям, связанным с использованием в ходе выборов преимуществ должностного или служебного положения. Автором проведен анализ различных материалов судебной практики, в том числе решений судебных органов Российской Федерации и Европейского Суда по правам человека. Особое внимание уделяется выводам Верховного суда Российской Федерации и Конституционного Суда Российской Федерации. Основными выводами проведенного исследования является то, что при привлечении к ответственности за использование в ходе избирательной кампании преимуществ должностного или служебного положения необходимо оценить кратность, характер, содержание, цель совершения этих действий. По мнению автора, российское законодательство, которое не предусматривает обязанность уходить в отпуск для лии, замещающих государственные и муниципальные должности, содержит возможности нарушения принципа равного избирательного права. В связи с этим необходимо распространить эту обязанность и на лиц, замещающих государственные и муниципальные должности.

Ключевые слова: ответственность, должностное положение, административный ресурс, агитация, выборы, избирательное право, судебное решение, избирательная комиссия, регистрация кандидата, закон.

Abstract. The research subject is the social relations, connected with the imposition of legal responsibility for the use of the official status during the electoral campaign. The author considers such use of the official status as one of the forms of abuse of rights. The particular attention of the authors of the Constitution of the Russian Federation to the guarantees of the equality of human and civil rights and freedoms has conditioned the appearance of the particular article, devoted to the restraint of use of the advantages of the official status during the elections, in the Federal Law "On the general guarantees of electoral rights and the right to participate in referendum of citizens of the Russian Federation". The author of the study analyzes various materials of judicial practice, including the decisions of courts of the Russian Federation and the European Court of Human Rights. Special attention is given to the conclusions of the Supreme Court of the Russian Federation and the Constitutional Court of the Russian Federation. The author concludes that when imposing the responsibility for the use of the advantages of the official status in the electoral campaign, it is necessary to assess the frequency, the character, the content and the purpose of these actions. In the author's opinion, Russian legislation, which doesn't allow for the compulsory leave of persons, filling state and municipal posts, creates the opportunities of violation of the equal suffrage principle. Therefore, it is necessary to extend this duty to persons, filling state and municipal posts.
\end{abstract}

Key words: election, suffrage, court judgement, administrative resource, official status, responsibility, campaigning , election committee, candidate registration, law.

И спользование преимуществ должностного или служебного положения в ходе избирательной кампании непосредственно связано с категорией злоупотребления правами. Как отмечается в литературе, возможность злоупотребления кроется в самой природе субъективного права[1, 132], реализация которого, несмотря на нарушения «духа» закона, может сохранять видимость легального поведения[2, 22].
Принцип запрета на злоупотребления правом закреплен в Конституции Российской Федерации и имеет общий характер для всех отраслей российской правовой системы. В соответствии с ч. 3 ст. 17 Конституции Российской Федерации осуществление прав и свобод человека и гражданина не должно нарушать права и свободы других лиц. В связи с этим необходимо отметить, что подход, избранный российским законодателем для предотвра- 


\section{Административное и муниципальное право 11 (107) • 2016}

щения случаев злоупотребления избирательными правами, нельзя признать идеальным. Анализ положений Федерального закона от 12 июня 2002 г. № Ф3-67 «Об основных гарантиях избирательных прав и права на участие в референдуме граждан Российской Федерации» позволяет вывести основную концепцию противодействия злоупотреблению избирательными правами, используемую в российских законах. Законодатель предлагает недопустимость злоупотребления правом рассматривать как обычную запрещающую норму, как предел осуществления субъективного права. В Федеральном законе от 19 сентября 1997 г. «Об основных гарантиях избирательных прав и права на участие в референдуме граждан Российской Федерации» особое внимание законодателя к проблеме предотвращения случаев злоупотребления некоторыми избирательными правами выражалось в том, что понятие «злоупотребление избирательными правами» было вынесено в название ст. 45 Закона «Недопустимость злоупотреблений правом на проведение агитации». В действующем Законе «Об основных гарантиях избирательных прав и права на участие в референдуме граждан Российской Федерации» проводится концепция закрепления рамок правомерного поведения субъектов избирательного процесса. Некоторое исключение составляет такая форма злоупотребления правами как использование преимуществ должностного или служебного положения в ходе избирательной кампании.

В соответствии с ч. 2 ст. 19 Конституции Российской Федерации, политико-правовой потенциал которой еще не реализован в полной мере [3, 13], государство гарантирует равенство прав и свобод человека и гражданина независимо от пола, расы, национальности, языка, происхождения, имущественного и должностного положения, места жительства, отношения к религии, убеждений, принадлежности к общественным объединениям, а также других обстоятельств.

Особое внимание авторов российского Основного закона к гарантиям равенства прав и свобод человека и гражданина независимо от должностного положения определило появление в Федеральном законе «Об основных гарантиях избирательных прав и права на участие в референдуме граждан Российской Федерации» отдельной статьи, посвященной ограничениям, связанным с использованием в ходе выборов преимуществ должностного или служебного положения, то есть того, что в политической практике называют «административный ресурс». Необходимость особого внимание к проблемам квалификации правонарушений, связанных с использованием преимуществ должностного или служебного положения в ходе избирательной кампании определяется еще и тем, что в соответствии со ст. 76 Федерального закона «Об основных гарантиях избирательных прав и права на участие в референдуме граждан РФ» неоднократность совершения подобных правонарушений является основанием для отмены регистрации кандидата.

Российское законодательство установило запреты на использование административного ресурса в ходе избирательной кампании для двух категорий лиц. К первой относятся лица, являющиеся кандидатами, и замещающие государственные или выборные муниципальные должности; находящиеся на государственной или муниципальной службе; являющиеся членами органов управления организаций (кроме политических партий), должностными лицами, журналистами, другими творческими работниками средств массовой информации. Вторую категорию составляют лица, не являющиеся кандидатами, замещающие государственной или выборные муниципальные должности; находящиеся на государственной или муниципальной службе; являющиеся членами органов управления организаций (кроме политических партий) [4, 46-47].

Возможности использования преимуществ должностного или служебного положения можно увидеть на всех стадиях избирательного процесса. Судья Конституционного Суда Российской Федерации С.М. Казанцев в Особом мнении к Постановлению Конституционного Суда Российской Федерации от 15 апреля 2016 г. [5] связал этот деликт с институтом досрочного голосования. Он отмечал, что избирательные права, будучи элементом конституционного статуса избирателя, являются в то же время и элементом публично-правового института выборов - в них воплощаются как личный интерес каждого конкретного избирателя в принятии непосредственного участия в управлении делами государства, так и публичный интерес, реализующийся в объективных итогах выборов и формировании на этой основе органов публичной власти. Вместе с тем, по смыслу ст. 1 Конституции Российской Федерации в их взаимосвязи, эти интересы могут вступать между собой в известное противоречие. Задачей федерального законодателя является такое построение государственных и общественных институтов, которое объективно способствовало бы развитию демократии на основе сочетания и взаимодействия публичных и личных интересов $[6,99]$.

В поисках этого баланса федеральным законодателем в последнее десятилетие были внесены значительные изменения в правовое регулирование избирательного механизма: от широкого использования досрочного голосования был осу- 
ществлен переход к его существенному ограничению. Причиной такого тренда стали неоднократные правонарушения, допускавшиеся в процессе применения досрочного голосования. Основным контингентом досрочно голосующих оказываются военнослужащие, государственные и муниципальные служащие, работники государственных и муниципальных учреждений, а также пенсионеры, что вызывает подозрения в злоупотреблении отдельных должностных лиц своим служебным положением. В настоящее время право предусмотреть возможность проведение досрочного голосования по выборам органов государственной власти субъектов Российской Федерации и органов местного самоуправления относится к компетенции субъекта Федерации. При этом в ходе процесса внесения изменений в законодательство, иногда очень активного, надо иметь в виду, что «взвесить» как на весах права и свободы человека и гражданина и конституционные ценности, ради которых они могут быть ограничены, определить абсолютный минимум, «ядерное содержание» права, неприкосновенное ни при каких условиях, - задача достаточно трудная как для законодателя, так и для Конституционного Суда РФ, однако такой естественно-правовой ориентир необходим во избежание умаления прав и свобод человека и гражданина и произвольного их ограничения, основанного на позитивистском правопонимании $[7,48]$.

Проблема использования преимуществ должностного или служебного положения находилась в центре внимания и Европейского Суда по правам человека. Он неоднократно в своих решениях обращал внимание на то, что лица, замещающие то или иное должностное положение, всегда будут иметь определенные преимущества в избирательном процессе. Так, в решении по делу «Гитонас (Gitonas) и другие против Греции» от 1 июля 1997 г., связанным с аннулированием результатов выборов на основании статьи 56 п. 3 Конституции Греции, Суд говорит о необходимости закрепления в законодательстве ограничений их использования. Проводя анализ этого конституционного положения, согласно которому «гражданские служащие и военнослужащие вообще, взявшие на себя в соответствии с законом обязательство состоять на службе на протяжении определенного срока, не могут объявляться кандидатами и избираться депутатами Парламента в течение срока действия этих обязательств», Суд отметил: «Что касается объективных критериев, по которым определяется неизбираемость и которые не дают возможности Высшему специальному суду принимать во внимание какие бы то ни было особенности конкретного дела, Суд не находит такую ситуацию неразумной; практически очень трудно доказать, что нахождение на государственной службе было использовано в избирательных целях». Суд отметил, что «эти ограничения введены с учетом реалий политической жизни Греции и имеют целью обеспечить политическую нейтральность государственной службы, независимость членов Парламента, соблюдения принципа разделения властей» [8].

Перечень действий, которые можно квалифицировать в качестве использования преимуществ должностного или служебного положения содержатся в п. 5 ст. 40 Федерального закона «Об основных гарантиях избирательных прав и права на участие в референдуме граждан Российской Федерации». В соответствии с Постановлением Пленума Верховного Суда РФ от 31 марта 2011 г. № 5 «0 практике рассмотрения судами дел о защите избирательных прав и права на участие в референдуме граждан РФ» этот перечень не подлежит расширительному толкованию. При оценке обстоятельств дел, связанных с использованием в ходе избирательной кампании и преимуществ должностного или служебного положения, необходимо принимать во внимание какое влияние оно оказало на процесс реализации субъективного избирательного права. В связи с этим нельзя в полной мере согласиться с мнением, что объектом использования преимуществ должностного или служебного положения выступает лишь комплекс общественных отношений, связанный с реализацией гражданами своего пассивного избирательного права, то есть совершение этого правонарушения не воздействует негативно на права избирателей[9, 74]. Любое правонарушение, связанное с использованием преимуществ должностного или служебного положения, непосредственно влияет на процесс реализации активного избирательного права, так как ставит правонарушителя в привилегированное положение по отношению к другим кандидатам, и как следствие - приводит к искажению содержания волеизъявления избирателей: нарушение равного статуса кандидатов негативно сказывается на условиях реализации активного избирательного права. Это актуально и в связи с тем, что особенностью правонарушений, связанных с использованием должностного или служебного положения является то, что их совершение возможно в рамках любой стадии избирательного процесса, и как следствие умаление избирательных прав может происходить в рамках любой электоральной процедуры.

На необходимость более глубокой оценки обстоятельств подобных правонарушения обращается внимание и в уже упомянутом выше Постановлении Пленума Верховного Суда РФ от 31 марта 2011 г. № 5 . В соответствии с ним при решении вопроса о том, является ли использование служебного или должностного положения достаточным осно- 


\section{Административное и муниципальное право 11 (107) • 2016}

ванием для применения судом предусмотренных Федеральным законом «Об основных гарантиях избирательных прав и права на участие в референдуме граждан РФ» неблагоприятных последствий для кандидата, избирательного объединения, необходимо, в частности, выяснять кратность, характер, содержание, цель совершения этих действий. Именно на основе проведенного анализа соотношения действий кандидата этим критериям, можно установить факт совершения правонарушения.

Неоднократность совершения правонарушений, связанных с использованием преимуществ должностного или служебного положения, стало основанием привлечения к ответственности одного из кандидатов в ходе проведения повторных выборов Саратовской областной Думы третьего созыва по Фрунзенскому одномандатному избирательному округу № 11. Окружная избирательная комиссия обратилась в суд с представлением об отмене регистрации кандидата в депутаты Саратовской областной Думы третьего созыва Ш. В обоснование представления было указано на то, что Ш. являясь главным редактором газеты «Отражение», учредителем которой является Саратовский общественный региональный благотворительный фонд поддержки пенсионеров, выпустил два номера газеты, целиком посвященные агитационным материалам в поддержку своей кандидатуры. В нарушение действующего избирательного законодательства Ш. не представил в окружную избирательную комиссию копии приказа об освобождении его на период выборов от должности главного редактора газеты, а следовательно, указанными действиями Ш. нарушил принцип равного избирательного права, использовав преимущества своего служебного положения.

В судебном заседании председатель избирательной комиссии дополнил основание к требованию об отмене регистрации теми обстоятельствами, что Ш. в нарушение действующего законодательства, будучи кандидатом в депутаты, проводил предвыборную агитацию в средстве массовой информации, не входящем в перечень изданий, утвержденный Саратовской областной избирательной комиссией. В кассационной жалобе Ш. указывал на необоснованность решения суда первой инстанции. Проверив материалы дела и обсудив доводы кассационной жалобы, Судебная коллегия по гражданским делам Верховного Суда Российской Федерации не нашла оснований для ее удовлетворения. По мнению Суда Ш. незаконно использовал возможности благотворительной организации и ее печатного орган и поставил себя в преимущественное положение относительно других кандидатов, нарушив принцип равных условий доступа к средствам массовой информации[10].
Избирательное законодательство старается обеспечить равное положение участников избирательной кампании путем ограничения прав кандидатов, занимающихся определенной деятельностью, воздействовать на избирательный процесс, используя свои профессиональные возможности. Одной из гарантий равенства субъектов пассивного избирательного права является «предвыборный отпуск» $[11,118]$, в который они должны уходить. В соответствии с ч. 2 ст. 40 Федерального закона «Об основных гарантиях избирательных прав и права на участие в референдуме граждан Российской Федерации» зарегистрированные кандидаты, находящиеся на государственной или муниципальной службе либо работающие в организациях, осуществляющих выпуск средств массовой информации, на время их участия в выборах освобождаются от выполнения должностных или служебных обязанностей и представляют в избирательную комиссию заверенные копии соответствующих приказов. По мнению Конституционного Суда РФ, «предвыборный отпуск» является оправданной мерой, введенной для того, чтобы использование этими лицами преимуществ своего должностного положения и возможностей влиять на процесс и итоги выборов исключалось, что, в свою очередь, обеспечивает реализацию конституционных гарантий свободы волеизъявления, права граждан на участие в демократических, свободных и периодических выборах как высшем непосредственном выражении принадлежащей народу власти[12]. Этот вывод российским органом конституционного контроля был сделан в отношении обязанности уходить в предвыборный отпуск руководителей высших исполнительных органов государственной власти субъектов Российской Федерации, зарегистрированных в качестве кандидатов на выборах.

В действующем российском избирательном законодательстве обязанность уходить в отпуск распространяется только на лиц, находящихся на государственной или муниципальной службе либо работающих в организациях, осуществляющих выпуск средств массовой информации. Кандидаты, замещающиеся муниципальные или государственные должности, были исключены из этого перечня в середине 2000-х гг.[13] Исходя из логики Конституционного Суда РФ, действующее законодательство допускает возможность использования этими лицами преимуществ своего должностного положения в форме влияния на ход избирательного процесса и итоги выборов.

Анализ избирательных кампаний показывает, что у правоприменителей вызывают трудности определение правового статуса должностных лиц, являющихся кандидатами. Это является следствием как недостатков законодательства, так и поли- 
тической практики. Особый интерес в этом контексте вызывает дело, связанное с попыткой отмены регистрации кандидата 3., являющегося во время избирательной кампании исполняющим обязанности мэра г. Новосибирска. В соответствии с ч. 2 ст. 39 Устава г. Новосибирска в случае досрочного прекращения полномочий мэра г. Новосибирска его полномочия в полном объеме исполняет первый заместитель. Вследствие этого 3., являясь на момент ухода мэра в отставку, первым его заместителем, на основании распоряжении мэрии Новосибирска от 10 января 2014 г. приступил к исполнению полномочий главы муниципального образования в полном объеме.

Обосновывая свое заявление в суд об отмене решения Новосибирской городской муниципальной избирательной комиссии от 3 марта 2014 г. «0 регистрации 3. кандидатом на должность мэра г. Новосибирска», кандидат С. ссылался на неоднократное использование 3. «преимуществ своего должностного положения, выразившихся в несоблюдении установленных законодательством ограничений, получении регулярного и монопольного доступа к средствам массовой информации». Заявитель считал, что «кандидат 3. неправомерно отказался от ухода в отпуск для участия в избирательной кампании, в результате чего 3., будучи муниципальным служащим, получил доступ к информационным муниципальным ресурсам».

Представитель 3. в возражении на заявление об отмене регистрации кандидата отметил, что «выборные должностные лица местного самоуправления (к которым относится мэр города Новосибирска) не являются муниципальными служащими. Таким образом, на лицо, замещающее должность мэра Новосибирска, не распространяется требование ч. 2 ст. 40 Федерального закона «Об основных гарантиях избирательных прав и права на участие в референдуме граждан РФ» об освобождении от выполнения должностных или служебных обязанностей».

Суд первой инстанции, рассматривая обстоятельства дела, обратил внимание, что статус 3. определяется как статус муниципального служащего, а не выборного должностного лица местного самоуправления. Поскольку, в соответствии со ст. 19 Федерального закона от 2 марта 2007 г. № 25-ФЗ «0 муниципальной службе в РФ» единственным фактом, подтверждающим прекращение статуса муниципального служащего, может быть только факт расторжения трудового договора (контракта). В суд не было представлено документальное подтверждение факта расторжения договора (контракта) 3. с мэрией Новосибирска. Более того, в представленной в суд копии трудовой книжки 3. отсутствовала запись о расторжении трудового договора о назначении на муниципальную службу на должность первого заместителя мэра г. Новосибирска. Суд отмечал, что поскольку 3. не вступал в должность мэра в установленном Уставом Новосибирска порядке, статус выборного должностного лица он не приобрел. Он лишь временно приостановил исполнение обязанностей заместителя мэра Новосибирска. Факт временного исполнения 3. обязанностей мэра г. Новосибирска, по мнению суда, не изменяет статус муниципального служащего, а лишь временно наделяет его полномочиями главы муниципального образования. Вследствие этого суд принял решении об удовлетворении требований заявителя [14]. Это решение было отменено Новосибирским областным судом [15]. Суд посчитал, что исполняющий обязанности мэра г. Новосибирска в полном объеме обладает полномочиями главы муниципального образования, и отказ от ухода в отпуск в период избирательной кампании нельзя рассматривать как неправомерный.

К сожалению, решение Новосибирского областного суда не было обжаловано в Верховный Суд РФ, и в настоящее время его позицию по этому делу мы знать не можем. Но более логичной представляется позиция суда первой инстанции, заключающаяся в том, что временное исполнение первым заместителем мэра обязанностей главы муниципального образования не изменило его статус как муниципального служащего. При этом расторжение служебного контракта с лицом замещающим должность первого заместителя мэра г. Новосибирска повлечет за собой невозможность исполнения этим лицом обязанностей мэра.

Делая выводы необходимо отметить, что при привлечении к ответственности за использование в ходе избирательной кампании преимуществ должностного или служебного положения необходимо оценить кратность, характер, содержание, цель совершения этих действий. Именно на основе проведенного анализа соотношения действий кандидата этим критериям, можно установить факт совершения правонарушения. При этом, даже признание факта использования в ходе избирательной кампании преимуществ должностного или служебного положения, не позволяет в будущем нивелировать те преимущества, которые были получены правонарушителем в ходе реализации определенных электоральных процедур. Применение такой санкции как отмена регистрации является довольно сложной процедурой, которую не всегда можно довести до конца в рамках избирательной кампании.

В этом контексте можно приветствовать предложение о том, что мерой ужесточения механизмов, препятствующих использованию должностного и служебного положения влиятельных лиц в процессе выборов, может являться признание 


\section{Административное и муниципальное право 11 (107) 2016}

предвыборной агитацией распространения информации через СМИ о профессиональной деятельности или исполнении служебных (должностных) обязанностей кандидатом, являющимся лицом, замещающим государственные или выборные муниципальные должности, государственным и муниципальным служащим, членом органа управления организации независимо от формы собственности (в организациях, высшим органом управления которых является собрание - членом органов, осуществляющих руководство деятельностью этих организаций), за исключением политических партий, неоднократно превышающей среднестати- стический объем соответствующей информации в течение последних трех лет срока исполнения таких полномочий такими лицами [16, 16-17].

При этом исходя из позиции Конституционного Суда РФ в отношении предвыборных отпусков, российское законодательство, которое не предусматривает обязанность уходить в отпуск для лиц, замещающих государственные и муниципальные должности, содержит возможности нарушения принципа равного избирательного права. В связи с этим необходимо распространить эту обязанность и на лиц, замещающих государственные и муниципальные должности.

\section{Библиография:}

1. Малиновский А.А. Злоупотребление субъективным правом. М.: Издательство «Юрлитинформ», 2007.352 с.

2. Кратенко М.В. Злоупотребление свободой договора: частноправовые и публично-правовые аспекты. М: Волтерс Клувер, 2010. 208 с.

3. Юсубов Э.С. Дискурс о стабильности Конституции Российской Федерации 1993 г. // Конституционное и муниципальное право. 2014. № 1. С. 13-16.

4. Зелинский Я.В. Вопросы юридической ответственности за использование преимуществ должностного или служебного положения в период избирательной кампании // Конституционное и муниципальное право. 2013. № 9. С. 46-47.

5. Постановление Конституционного Суда РФ от 15 апреля 2014 г. № 11-П «По делу о проверке конституционности пункта 1 статьи 65 Федерального закона "Об основных гарантиях избирательных прав и права на участие в референдуме граждан Российской Федерации" в связи с запросом Законодательного Собрания Владимирской области» // Собрание законодательства РФ. 2014. № 16. Ст. 1922.

6. Шерстобоев О.Н. Теория интереса в административно-правовом измерении: на примере высылки иностранных граждан за пределы принимающего государства // Российский юридический журнал. 2014. № 3. С. 99-108.

7. Черепанов В.А. К вопросу об ограничении пассивного избирательного права // Государство и право. 2015. C. 47-54.

8. http://europeancourt.ru/resheniya-evropejskogo-suda-na-russkom-yazyke/gitonas-i-drugie-protiv (дата доступа 15 мая 2016 г.).

9. Шин А.Г. Конституционно-правовая ответственность кандидатов в депутаты или на выборные должности за использование на выборах преимуществ своего должностного (служебного) положения. Иркутск, 2013. 215 с.

10. Определение Верховного Суда РФ от 29 ноября 2002 г. Дело № 32-02-20 Определение Верховного Суда РФ от 29.11.2002 N 32-Г02-20 «Представление избирательной комиссии об отмене регистрации кандидата в депутаты областной Думы удовлетворено правомерно, так как кандидатом были допущены существенные нарушения избирательного законодательства при проведении предвыборной агитации» // СПС «КонсультантПлюс».

11. Право избирать и быть избранным в российских политических реалиях: основные конституционно-правовые проблемы. Рук. авт. кол и отв. ред. проф. Авакьян С.А. М., 2015. 680 с.

12. Определение Конституционно Суда Российской Федерации от 25 декабря 2003 г. № 457-0 «0б отказе в принятии к рассмотрению запросов губернатора Вологодской области, губернатора Ленинградской области, Правительства Мурманской области и обращения политсовета Мурманского регионального отделения политической партии "Единая Россия" о проверке конституционности пункта 2 статьи 40 Федерального закона "Об основных гарантиях избирательных прав и права на участие в референдуме граждан РФ" и пункта 2 статьи 49 Федерального закона "О выборах депутатов Государственной Думы Федерального Собрания РФ» // Вестник Конституционного Суда РФ. 2004. № 3. С. 17.

13. Федеральный закон от 21 июня 2005 г. № 93-Ф3 «0 внесении изменений в законодательные акты Российской Федерации о выборах и референдумах и иные законодательные акты РФ» // Собрание законодательства РФ. 2005. № 30. (ч. 1). Ст. 3104.

14. Решение Центрального районного суда г. Новосибирска от 21 марта 2014 г. Дело № 2-3061/2014.

15. Апелляционное определение Судебной коллегии по гражданским делам Новосибирского областного суда от 29 марта 2014 г. // Дело № 33-3526-2014.

16. Вискулова В.В. Гарантии избирательных прав граждан современной России: вопросы теории и практики. Автореф. на соиск. ученой степени доктора юридических наук. М., 2013. 48 с.

17. Аничкин Е.С., Рудт Ю.А. Соотношение универсальных и национальных конституционных ценностей в странах Европейского союза // Вестник алтайской академии экономики и права. 2013. № 2. С. 86-88.

18. Любарев А.Е. Соответствуют ли российские выборы своему конституционному предназначению // Право и политика. 2013. № 13. С. 1903 - 1915. DOI: 10.7256/1811-9018.2013.13.10158.

19. Липинский Д.А., Станкин А.Н. О роли решений Конституционного Суда в формировании системы конституционной ответственности // Юридические исследования. - 2016. - 10. - С. 50 - 62. DOI: 10.7256/24097136.2016.10.19460. URL: http://www.e-notabene.ru/lr/article_19460.html 
20. Пирбудагова В.И. Юридическая ответственность должностных лиц в Российской Федерации: проблемы законодательного обеспечения // Политика и Общество. 2012. № 5. С. 29 - 34.

\section{References (transliterated):}

1. Malinovskii A.A. Zloupotreblenie sub"ektivnym pravom. M.: Izdatel'stvo «Yurlitinform», 2007. $352 \mathrm{s.}$

2. Kratenko M.V. Zloupotreblenie svobodoi dogovora: chastnopravovye i publichno-pravovye aspekty. M: Volters Kluver, 2010. $208 \mathrm{~s}$.

3. Yusubov E.S. Diskurs o stabil'nosti Konstitutsii Rossiiskoi Federatsii 1993 g. // Konstitutsionnoe i munitsipal'noe pravo. 2014. № 1. S. 13-16.

4. Zelinskii Ya.V. Voprosy yuridicheskoi otvetstvennosti za ispol'zovanie preimushchestv dolzhnostnogo ili sluzhebnogo polozheniya v period izbiratel'noi kampanii // Konstitutsionnoe i munitsipal'noe pravo. 2013. № 9. S. 46-47.

5. Postanovlenie Konstitutsionnogo Suda RF ot 15 aprelya 2014 g. № $11-\mathrm{P}$ «Po delu o proverke konstitutsionnosti punkta 1 stat'i 65 Federal'nogo zakona "Ob osnovnykh garantiyakh izbiratel'nykh prav i prava na uchastie v referendume grazhdan Rossiiskoi Federatsii" v svyazi s zaprosom Zakonodatel'nogo Sobraniya Vladimirskoi oblasti» // Sobranie zakonodatel'stva RF. 2014. № 16. St. 1922.

6. Sherstoboev O.N. Teoriya interesa v administrativno-pravovom izmerenii: na primere vysylki inostrannykh grazhdan za predely prinimayushchego gosudarstva // Rossiiskii yuridicheskii zhurnal. 2014. № 3. S. 99-108.

7. Cherepanov V.A. K voprosu ob ogranichenii passivnogo izbiratel'nogo prava // Gosudarstvo i pravo. 2015. № 12. S. $47-54$.

8. http://europeancourt.ru/resheniya-evropejskogo-suda-na-russkom-yazyke/gitonas-i-drugie-protiv (data dostupa 15 maya 2016 g.).

9. Shin A.G. Konstitutsionno-pravovaya otvetstvennost' kandidatov v deputaty ili na vybornye dolzhnosti za ispol'zovanie na vyborakh preimushchestv svoego dolzhnostnogo (sluzhebnogo) polozheniya. Irkutsk, 2013. $215 \mathrm{~s}$.

10. Opredelenie Verkhovnogo Suda RF ot 29 noyabrya 2002 g. Delo № 32-02-20 Opredelenie Verkhovnogo Suda RF ot 29.11.2002 N 32-G02-20 «Predstavlenie izbiratel'noi komissii ob otmene registratsii kandidata v deputaty oblastnoi Dumy udovletvoreno pravomerno, tak kak kandidatom byli dopushcheny sushchestvennye narusheniya izbiratel'nogo zakonodatel'stva pri provedenii predvybornoi agitatsii» // SPS «Konsul'tantPlyus».

11. Pravo izbirat' i byt' izbrannym v rossiiskikh politicheskikh realiyakh: osnovnye konstitutsionno-pravovye problemy. Ruk. avt. kol i otv. red. prof. Avak'yan S.A. M., 2015. 680 s.

12. Opredelenie Konstitutsionno Suda Rossiiskoi Federatsii ot 25 dekabrya 2003 g. № 457-0 «Ob otkaze v prinyatii k rassmotreniyu zaprosov gubernatora Vologodskoi oblasti, gubernatora Leningradskoi oblasti, Pravitel'stva Murmanskoi oblasti i obrashcheniya politsoveta Murmanskogo regional'nogo otdeleniya politicheskoi partii "Edinaya Rossiya" o proverke konstitutsionnosti punkta 2 stat'i 40 Federal'nogo zakona "Ob osnovnykh garantiyakh izbiratel'nykh prav i prava na uchastie v referendume grazhdan RF" i punkta 2 stat'i 49 Federal'nogo zakona "O vyborakh deputatov Gosudarstvennoi Dumy Federal'nogo Sobraniya RF» // Vestnik Konstitutsionnogo Suda RF. 2004. № 3. S. 17.

13. Federal'nyi zakon ot 21 iyunya 2005 g. № $93-\mathrm{FZ} « 0$ vnesenii izmenenii v zakonodatel'nye akty Rossiiskoi Federatsii o vyborakh i referendumakh i inye zakonodatel'nye akty RF» // Sobranie zakonodatel'stva RF. 2005. № 30. (ch. 1). St. 3104.

14. Reshenie Tsentral'nogo raionnogo suda g. Novosibirska ot 21 marta 2014 g. Delo № 2-3061/2014.

15. Apellyatsionnoe opredelenie Sudebnoi kollegii po grazhdanskim delam Novosibirskogo oblastnogo suda ot 29 marta 2014 g. // Delo № 33-3526-2014.

16. Viskulova V.V. Garantii izbiratel'nykh prav grazhdan sovremennoi Rossii: voprosy teorii i praktiki. Avtoref. na soisk. uchenoi stepeni doktora yuridicheskikh nauk. M., 2013. $48 \mathrm{~s}$.

17. Anichkin E.S., Rudt Yu.A. Sootnoshenie universal'nykh i natsional'nykh konstitutsionnykh tsennostei v stranakh Evropeiskogo soyuza // Vestnik altaiskoi akademii ekonomiki i prava. 2013. № 2. S. 86-88.

18. Lyubarev A.E. Sootvetstvuyut li rossiiskie vybory svoemu konstitutsionnomu prednaznacheniyu // Pravo i politika. 2013. № 13. C. 1903 - 1915. DOI: 10.7256/1811-9018.2013.13.10158.

19. Lipinskii D.A.,Stankin A.N.O roli reshenii KonstitutsionnogoSudav formirovaniisistemykonstitutsionnoi otvetstvennosti// Yuridicheskie issledovaniya. - 2016. - 10. - C. 50 - 62. DOI: 10.7256/2409-7136.2016.10.19460. URL: http://www.enotabene.ru/lr/article_19460.html

20. Pirbudagova V.I. Yuridicheskaya otvetstvennost' dolzhnostnykh lits v Rossiiskoi Federatsii: problemy zakonodatel'nogo obespecheniya // Politika i Obshchestvo. 2012. № 5. C. 29 - 34. 